\title{
Design and Implementation of Electronic Student Affairs System
}

\author{
Adnan Mohsin Abdulazeez ${ }^{1}$, Subhi R. M. Zeebaree ${ }^{2}$, Mohammed A. M. Sadeeq ${ }^{3}$ \\ ${ }^{1}$ Duhok Polytechnic University, Duhok, Kurdistan Region - Iraq \\ ${ }^{2}$ College of Engineering, Nawroz University, Duhok, Kurdistan Region - Iraq \\ ${ }^{3}$ Duhok Polytechnic University, Duhok, Kurdistan Region - Iraq
}

\begin{abstract}
This paper produces an efficient proposed student affairs system for Duhok Polytechnic University (DPU) called DPU Electronic Student Affairs System (DPU-ESAS). The proposed system consists of thirteen modules that provide four group of services, which are (student services: registration, ID card, postponement, transfer and waiver, certificate of graduation, Non-failure year and absence), (department services: plan acceptance and minimum limits), and (institution service: decisions approving), and (university service: authentication, decision approving and statistics). The proposed DPU-ESAS is designed according to the structure of DPU, which contains two different study systems. These systems are four years studying system depended at the colleges, and two years studying system for the institutes. The obtained results recorded and evaluated via special questionnaires form (system usability scale) that checked by students and staff of the same institutions. The evaluation score of the questionnaire is $(72.44 \%)$ which can be considered as a good percentage.
\end{abstract}

KEYWORDS: E-Government, E-University, E-Student Registration, E-Student Affairs.

\section{INTRODUCTION}

The online term in regards to computer technology and communications mean that the computer connects to the network. Successful online support services aid for both students and faculty members. It rises, the number of the population and the diversity of student population, especially in the proficiency with a technology of students [1]. Dynamic cultural complex for students in universities has become increasingly, making the work of professionals Student Affairs (SA) challenge ever more. Issues and concerns, which include important variables such race, age, gender and other social variables that contribute to the difficulty in creating an environment for all students. Although despite the efforts of higher education to develop methods to respond to a diverse student group and results, SA professionals play an essential role when multicultural issues on campus. This position invites for the integration of multicultural awareness, knowledge and practice [2]. By joining goals with form and function, SA

Academic Journal of Nawroz University

(AJNU) Volume 7, No 3 (2018).

Received 25 Feb 2018;

Regular research paper : Published 20 June 2018

Corresponding author's e-mail : president@dpu.edu.krd

Copyright (C2018 Adnan Mohsin Abdulazeez.

This is an open access article distributed under the Creative

Commons Attribution License. divisions can more purposely identify their objectives and the optimal ways to achieve them. In other words, how the SA division and practice are structured. They will make an enormous difference to the overall purpose of SA. The selection of model and the deliberations on that choice can influence how decisions are made, programs are instituted, and policy is set within an SA division and its institutional context [3]. Too often, the divisions of SA at colleges and universities appear to be organizationally separate from other units, such as academic and business affairs, within the same institution. However, it is only clear on the structural drawings. Best and most effective integrated student (organizations, academic, business and affairs). In a manner of focusing on all resources of the primary goal of higher education, student education, personal development, and involves all full organizational unit in achieving its mission. Mission statements and the institution [4]. (AL-Zuabi 2015) [5], proposed a database system to convert manual procedures in the Student Affairs Unit (SAU) of the interruption, denial, and medical excuses to computerized procedures within a single database. This database was designed for data entry and filter lists of hindering and denial by the SAU that are computerized, results in accuracy as well as reduce the time and effort. Data entry of excuses by the computerized way and coding them, the results were in accuracy and prevented the duplication of the same excuses, and decreased the time needed to find a 
particular student excuse. However, this system designed for some few parts belong just absence module related with the medical leaves. Another important limitation (i.e. drawback) of [5] is that it was designed by Microsoft Access, that not support the online implementation.(Alsayed, 2014) [6], proposed Electronic Forms (E-forms) that represented an easy way to communicate efficiently with students. At present, universities are still using traditional systems for communications, where efforts to improve the system is to process lethargic. And because most of these universities are still using the student forms manually, the introduction of E-forms speeds up the whole process and affect positively in communication efficiency. Also, the inconvenience of doing several visits to the university is sometimes trouble, but due to the lack of Information Technology (IT) development in the universities, and this is the usual pattern is still seen in most universities. So, Alsayed proposed to use E-forms in universities to help students and university staff to communicate effectively and efficiently. This work deals with designing twelve forms but all are belong just four modules which are: Leaves, Statistics, Plan Acceptance and Registration modules. (Cheng-Hui 2014) [7], proposed a system that consists of: management system, the management of the school register, performance management, account management, personal management, and data management of six modules. At first he briefly research background and the research goal and significance. Also, introduced some of the techniques and the theory of knowledge appropriate for the development of the system. Then, the process management system design and implementation have been addressed. Which included the design of backstage supporter's database, system' homepage design, etc. Finally carried on the test system, and then summarized the questions and the method of solution that encountered in the process of development of the system. This system related just with student information management. In general, the implementation of this system can be considered as just two modules: Registration and Statistics Modules. Hence, this is the first stage of student affairs. As a conclusion for comparing the proposed DPU-ESAS with the pervious works, it can be observed that the scope of altogether previous works is limited by the modules: Absence, Statistics, Plan Acceptance, Registration, Leaves, and Exam Committee. But in compare with the proposed DPU-ESAS, there are two main points:

Just (Leave and Exam Committee) modules are not addressed in DPU-ESAS. The Leave module not applied because there is no practical E-government system in Kurdistan, hence the communications with Health ministry will be applied manually. The Exam Committee has no relation with student affairs structure, so there is no need to it. There are other five modules addressed in DPU-ESAS and not been dis cussed by the previous works: Student ID card, Transfer and Waiver, Student Postponement, Minimum Limits and Certificate of graduation. The main aim of this work is to design and implement a proposed Electronic Student Affairs System (ESAS) to be used at Duhok Polytechnic University (DPU) instead of the handwrite system that is currently depended at all Kurdistan Universities. The proposed system will be used to combine all DPU seven campuses in one system to be managed electronically. This system aims to leave the paper system and trend to electronic system to service thirteen institutions: 0ne presidency, four colleges and eight institutions.

\section{STUDENT AFFAIRS IN HIGHER EDUCATION}

Kammer [8] defined SA personnel as those employees who work in student services units, generally student activities (Inc. fraternity and sorority advisement), residence life, counseling, career development, advisement, student health, orientation, student conduct, and campus ministry. Student Affairs is a vital path to the presidency as individuals in this area possess the necessary skills to be an effective leader of the college [9]. Today, the function of student affairs has been identified as a phenomenon that has evolved over time into a practical approach to student development within the higher education system declared that responding to society's changing needs. Student affairs has assumed numerous essential roles within colleges and universities and continued to expand its role [10, 11]. The most important role of the various roles and responsibilities of student affairs administrators is that of educator, asserting that student affairs administrators can be good managers and problem solvers, but if they are not actively engaged in advancing the education of students, then they have abandoned their most important obligation as professionals [12]. The fundamental domain of student affairs administration as it enters the twenty-first century is education, carried out in an integrated and collaborative manner with faculty and staff members from other major institutional, organizational units [13]. The partnership means more than working as allies or occasional collaborators, by academic affairs and student affairs divisions must be colleagues with shared values, goals, and language, committed to creating a singular cohesive educational environment and activity for each student [14].

\subsection{Requirements of Proposed DPU-ESAS Design}

The proposed system includes the investigation of the functional and non-functional requirements together with the required software and hardware that are necessary for the design and implementation. To design and implement E-SAS for DPU some requirements are needed to achieve 
this project such as: functional and non-functional requirements, hardware and software requirements. Functional requirements mean what a system is supposed to accomplish and the services that applied. Which person (user) has the authority to? enter the data into the database system, prepare system reports and other outputs, and identifying the descriptions of data to be entered into the system. There are four main types of functional requirements: Student (Sign in, Fill application form, Submit Application form and Track Application), University Employees (Sign in, View Applications and Approve/ Deny after verification), Application services, and System. Non-functional requirements or sometimes called system qualities refer to all requirements that describe the system attributes such as: Security, Usability, Reliability, Accessibility, Extensibility and Availability. To design an efficient web based development of SAS for DPU with multiple modules to perform many tasks, there is a need to some software such as: Windows operating system, MySQL Database (phpMyadmin), HTML, PHP, Ajax and jQuery, CSS, Bootstrap, Web browser, and Internet service. There are two sides for hardware implementation related with hardware requirements: Server-side: As test implementation for the proposed system, there will be only one server (for both of WA and DBS) to be considered as two Tier Architecture 2TA. Client-side: The client-side consists of two parts: Internal Clients and External Clients. Adding to the above hosts, the proposed system needs to the related peripheral devices for each unit such as: Scanners, Printers, Internet service provider.

\subsubsection{Proposed DPU-ESAS Modules and Admins}

The proposed DPU-ESAS has been designed to provide important students services at DPU. This system consists of thirteen modules and three Admin types. The admins are: University, Institutions and Head of Departments Admins. University admin authorizes all Institutions and Head of departments admins. Also, university admin has full authorization of all system's modules. While the institution admin has authority of the students affairs unit belong his institution. Finally, Head of Department admin has the authority of the tasks combined between his students and the student affairs unit of the institution. Each module is designed to meet student affairs requirements at DPU to be used friendly using: add, view, edit, delete and print. The admins and designed modules for DPU-ESAS are: University Students Affairs Admin (USAA), Institution Students Affairs Admin (ISAA), Head of Department Admin (HDA), Students Affairs Directorate (SAD) module, Students Affairs Unit (SAU) module, Department module, Student Registration (SR) module, Student ID Card (SIDC) module, Transfer and Waiver (TW) module, Student Postponement (SP) module, Plan Acceptance (PA) module, Graduate Certificate (GC) module, Minimum Limits (ML) module, Student Absence (StAb) module, Non-Failure Year module. and Statistics module. The structure of modules connections for the proposed DPU-ESAS illustrated in Figure (1). While, the details of these interconnections among the above thirteen modules are illustrated in Figure (2). The proposed system consists of thirteen modules to provide the needed services. Figure (2) represents the general structure of the proposed system. 


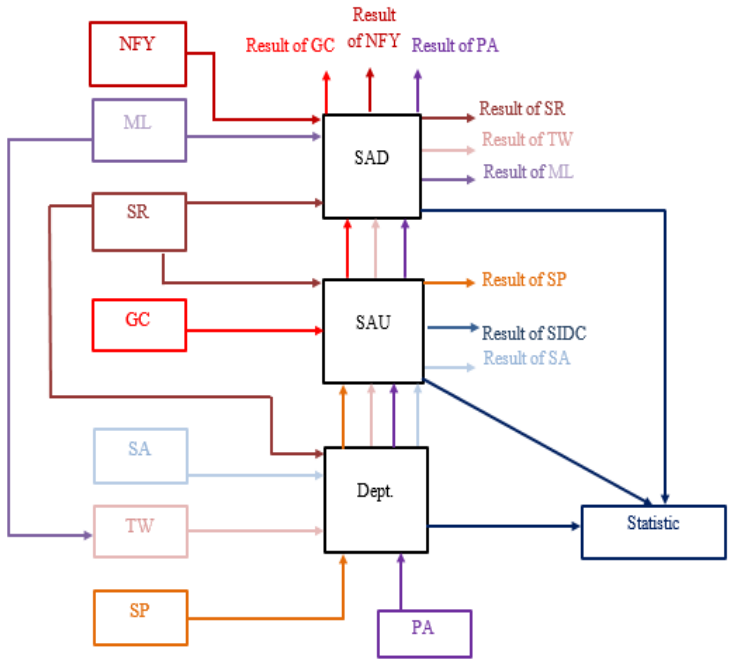

Fig (1) : Modules connections of DPU- ESAS

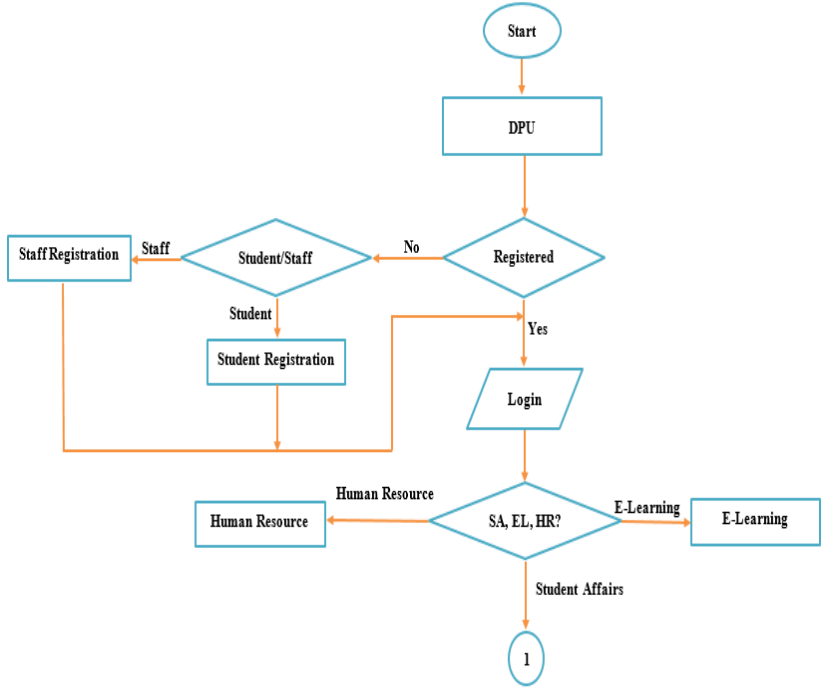

Fig (2.A) : Modules connections of DPU- ESAS 


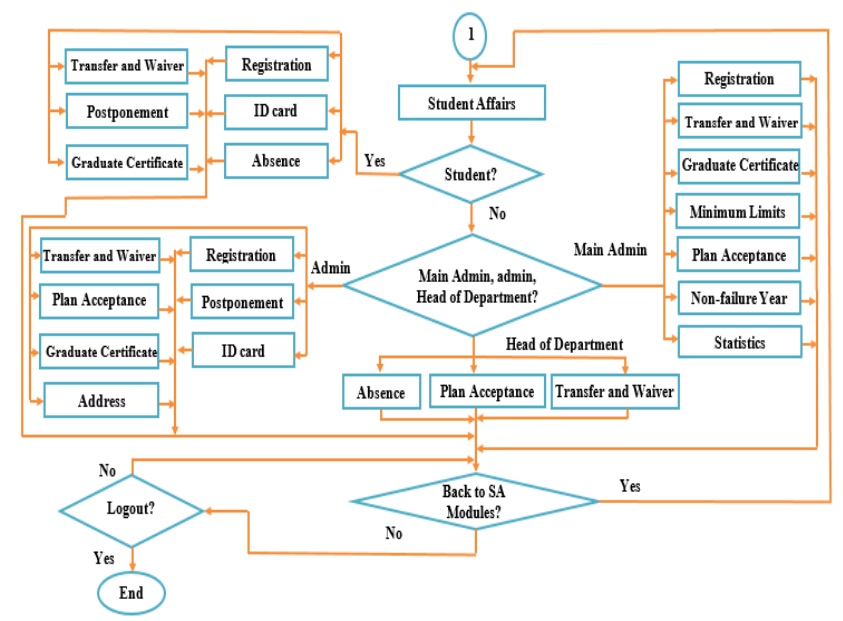

Fig (2.B) : Modules connections of DPU- ESAS

\subsubsection{Implementation and Evaluation of The Proposed Esas}

Figure (3) shows the EDPU homepage, so each authorized person must be login to the system, then can access the student affairs system homepage shown in Figure (4). While Figures (5, 6 and 7) represent: department plan acceptance and minimum limits, student registration, ID card, TW, postponement and absence, and student graduate Certificate, respectively.
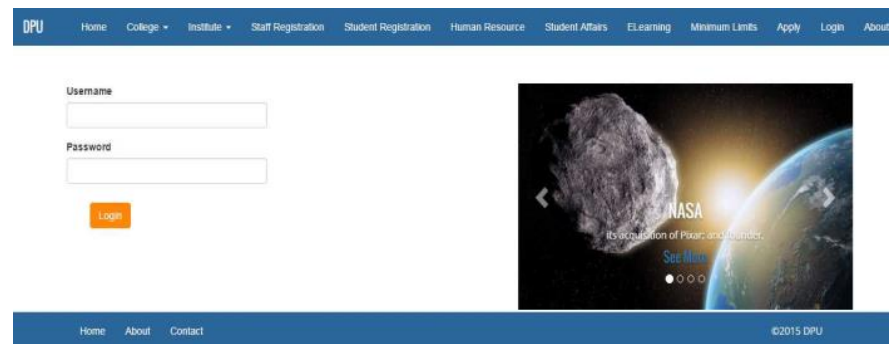

Fig (3) : Home Page

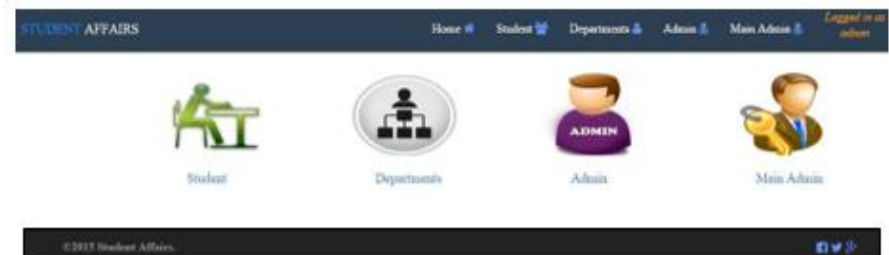

Fig (4) : Student Affairs Page

\section{Illustrative Example}

- Student Registration: zaid sleman mohamad sleman.

- Student ID card: aram ayoub serab azez.

- Transfer \& waiver: pawan abdulkarem omar noman.

- Student postponed: sema mohamad ameen hamed.

- Student absence: berikhan shaban maher zaenal.

- Graduate certificate: sema mohamad ameen hamed. 
- Plan Acceptance: Duhok technical institute.

- Minimum limits: Duhok technical institute.

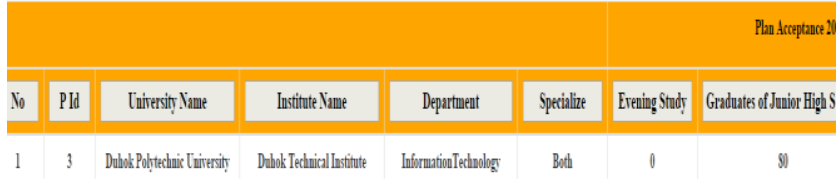

\begin{tabular}{|c|c|c|c|c|c|}
\hline \multicolumn{6}{|c|}{ Vinimum_ limits of 2015_2016-2016_2017 } \\
\hline 10 & Nin_Id & Institute_eme & Departuent & Departwat Degree 0 f 2016 & Departwent Degre 0 of 2015 \\
\hline 1 & 1 & Dahok Fechural Instititte & Information Technobgeg & 450 & Hs \\
\hline
\end{tabular}

Fig (5) : Department plan acceptance and minimum limits

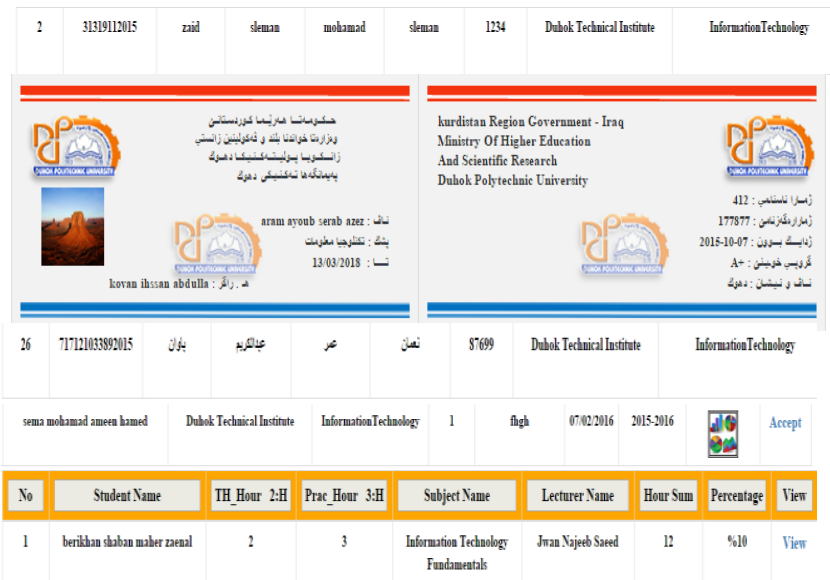

Fig (6) : Student registration, ID card, TW, Postponement and absence

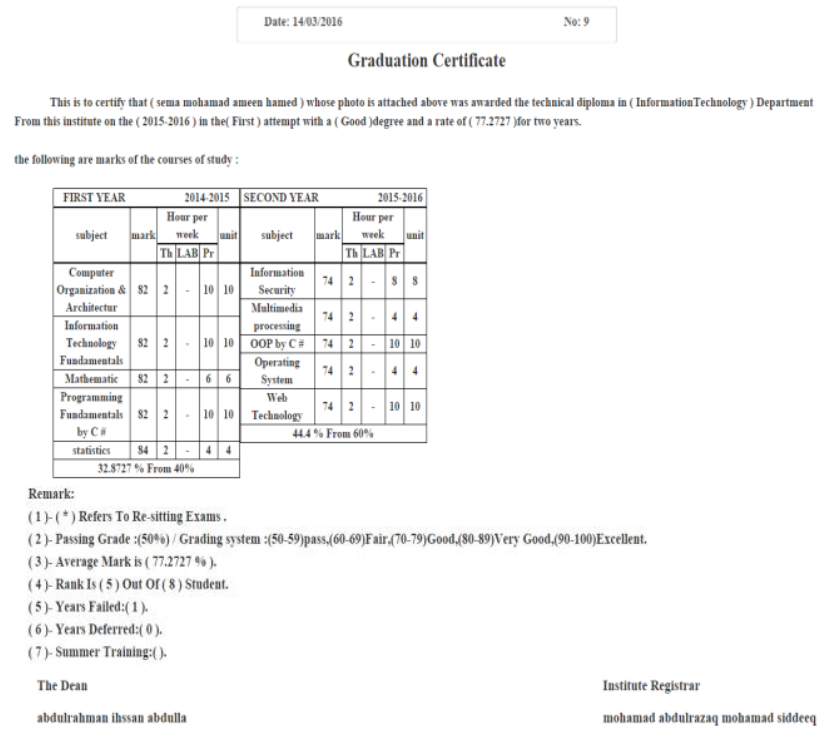

Fig (7) : Student graduate Certificate 
The proposed DPU-ESAS has been implemented practically at six institutions: DPU presidency, Duhok Engineering Technical College (DETC), Shekhan Health Technical College (SHTC), Duhok Technology Institute (DTI), Zakho Technical Institute, Shekhan Technical Institute (STI). These institutions are distributed over three campuses: Duhok, Zakho and Shekhan. The implementation has been evaluated via one of the efficient systems called System Usability Scale (SUS). The SUS is a reliable tool used to evaluate application usability and represents a self-reported survey metric. The SUS scores are in a 100.00 scale, which refers to the higher level of effectiveness, efficiency, and satisfaction in the use of the system. This questionnaire consists of ten questions to provide variations the SUS. These questions prepare average user satisfaction or dissatisfaction on a five-point scale. The odd-questions are positively worded and the even-questions are negatively worded [15]. The testing (implementation) of the system has been performed by: USAA, ISAAs, SAU staff, HD, Lecturers and Students. There were (98) of the system's users presented with a short brief about the DPU-ESAS and on the SUS. The same users participated with the testing and evaluation processes. The evaluation process helps to find the strengths and weaknesses of the current system to collect data for the investigation. The main purpose of this questionnaire is to evaluate the usability of the DPU-ESAS including: effectiveness, efficiency and satisfaction from the system's user viewpoint. The provided system is generally perceived to be acceptable depending on the SUS total score which is (72.244). Figure (8) represents mean survey results.

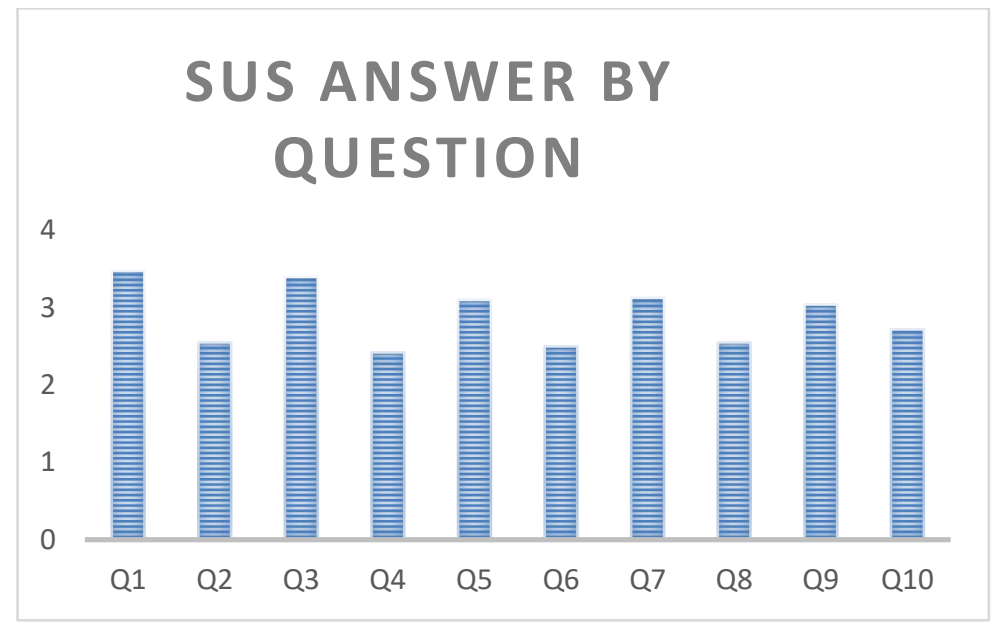

Fig (8) : Mean Survey Results

\section{CONCLUSIONS}

1. Web-based student affairs system in professional style has been designed and implemented to Duhok Polytechnic University named DPU-ESAS. An efficient mechanism of the student affairs services can be provided within the proposed DPU-ESAS to be applied for all Kurdistan Universities and converting their work flow from traditional-style to an electronic-based one. The proposed system will be used to combine all DPU eight campuses (including: presidency, four colleges and eight institutes) in one system to be managed electronically.

2. The proposed DPU-ESAS enhances the contact among the: DPU student affairs staff, Lecturers and students remotely with full flexibility. The contact style will be done via Internet, and the submission's response will be performed via DPU website, and any request or response will be done via E-mails.

3. The DPU-ESAS has been designed with economiccost in directions: money-consumed, time-consumed, lessefforts, more-accurate, minimizing number of visits and even minimizing environment pollution effects. So, this system can be copied usefully to any other university inside Kurdistan Region or Iraq.

\section{REFERENCES}

1. B. L. Bruso, (2001), "Treating soil, sediment or sludge contaminated with organic comounds: adding ferrous (fe+ 2) ion; agitating soil; measuring and adjusting ph; adding hydrogen peroxide as needed; agitating soil," ed: Google Patents.

2. R. Pope, A. Reynolds, J. Mueller, and H. Cheatham, (2004), "Multicultural competence in student affairs," San Francisco, CA.

3. K. Manning, J. Kinzie, and J. H. Schuh, (2013), One size does not fit all: Traditional and innovative models of student affairs practice: Routledge.

4. M. J. Barr, (2000), "The importance of institutional mission," The handbook of student affairs administration, pp. 25-36.

5. L. K. AL-Zuabi, (2015), "Designing and Building a Database of Denial and Excuses for Student Affairs Unit".

6. D. I. Alsayed, (2014), "ELECTRONIC STUDENTFORM MANAGEMENT SYSTEM". 
7. Y. Cheng-Hui, (2014), "Design and Implementation of Students' Information Management System (SIMS) Based on ASP," in 2014 International Conference on Economic Management and Trade Cooperation (EMTC 2014).

8. R. T. J. Kammer, (2008), Chief Student Affairs and Academic Affairs Officers' Perceptions of Counseling Centers' Value in Fulfilling Institutional Mission: ProQuest.

9. Y. Galloway. (2008). Tips on getting a community college presidency. Women in Higher Education.Retrieved December 28, 2009.http://www.wihe.com. Cited by Martin Q. 2010. Nontraditional pathways to the presidency: A student affairs approach. In: NORTHERN ILLINOIS UNIVERSITY.

10. L. M. Clement and S. T. Rickard, (1992), Effective Leadership in Student Services. Voices from the Field: ERIC.
11. A. Sandeen, (2004), "Educating the whole student: The growing academic importance of student affairs," Change: The Magazine of Higher Learning, vol. 36, pp. 28-33.

12. A. Sandeen, (1991), The Chief Student Affairs Officer: Leader, Manager, Mediator, Educator: ERIC.

13. D. Creamer, R. B. Winston, and T. Miller, (2001), "The professional student affairs administrator: Roles and functions," The professional student affairs administrator: Educator, leader, and manager, pp. 3-38. 14. B. W. Colwell, (2006), "Partners in a community of learners: Student and academic affairs at small colleges," New Directions for Student Services, vol. 2006, pp. 53-66.

15. A. Bangor, P. Kortum, and J. Miller, (2009), "Determining what individual SUS scores mean: Adding an adjective rating scale," Journal of usability studies, vol. $4, \quad$ pp. 114-123. 